\title{
Making Implicit Assumptions Explicit in the Costing of Informal Care: The Case of Head and Neck Cancer in Ireland
}

\author{
Paul Hanly ${ }^{1} \cdot$ Rebecca Maguire $^{1} \cdot$ Myles Balfe $^{2} \cdot$ Eleanor O'Sullivan $^{2} \cdot$ \\ Linda Sharp ${ }^{3}$
}

Published online: 15 February 2017

(c) Springer International Publishing Switzerland 2017

\begin{abstract}
Background From a health service perspective, informal care is often viewed as a potentially cost-effective way of transferring costs out of the formal healthcare sector. However, informal care is not a free resource.

Objective Our objective was to assess the impact of alternative valuation methods and key assumptions on the cost of informal care.

Methods Informal carers who assisted in the care of a head and neck cancer survivor for at least 1 year were sent a postal questionnaire during January-June 2014 requesting information on time spent on caring tasks in the month prior to the survey. Time was costed using the opportunity cost approach (OCA; base-case) and the generalist (GRCA) and specialist (SRCA) replacement cost approaches. The impact on results of how household work and informal carers not in paid employment are treated were investigated.
\end{abstract}

Paul Hanly

paul.hanly@ncirl.ie

Rebecca Maguire

rebecca.maguire@ncirl.ie

Myles Balfe

m.balfe@ucc.ie

Eleanor O'Sullivan

Eleanor.osullivan@ucc.ie

Linda Sharp

linda.sharp@ncl.ac.uk

National College of Ireland, Mayor Street, Dublin 1, Ireland

2 University College Cork, Cork, Ireland

3 Newcastle University, Newcastle upon Tyne, England
Results We estimated a cost of $€ 20,613$ annually in the base case (OCA - mean wage) for informal care. The GRCA and SRCA equivalent costs were $36 \%(€ 13,196)$ and $31 \%(€ 14,196)$ lower, respectively. In the extreme scenario of applying a 'zero' opportunity cost to carers not in paid employment, costs fell by $67 \%$ below the base case. Conclusion While the choice of costing method is important for monetary valuation, the sociodemographic and economic characteristics of the underlying population can be equally so. This is especially important given the heterogeneous treatment of older carers, female carers and carers not in paid employment in the OCA. To limit this, we would suggest using the SRCA to value informal care across heterogeneous carer populations.

\section{Key Points for Decision Makers}

The socioeconomic characteristics of carer populations can have a substantial impact on estimates of the value of informal care and therefore should be made explicit in analyses.

Often implicit assumptions, such as the treatment of carers not in paid employment, can alter the value of informal care to a greater degree than the valuation type chosen.

The use of the specialist replacement cost approach is advocated to value informal care across heterogeneous carer populations. 


\section{Introduction}

The pervading public health perspective views informal care as a cost-effective way of transferring costs from the formal budgeted sector to the informal sector [1]. However, informal care is not a free resource. From the societal perspective [2], informal care, although not formally reimbursed by the market, does engender economic costs.

Time is a limited resource for individuals and therefore the allocation of time to caring reduces the amount available for other activities. This can result in an opportunity cost, in which paid work, or the potential of paid work, is foregone [3-5]. In other cases, where care cannot be provided to the dependent, formal care services will need to be purchased [3,4]. This gives rise to the two dominant valuation approaches in the literature [6]: the opportunity cost approach (OCA) and the replacement cost approach (RCA). Although debate abounds on the most appropriate valuation method, a range of additional factors-including value judgements and implicit methodological assumptions-also impact on informal care costs. Few empirical studies examine the impact of these [7-9].

A key value judgement underpinning the OCA is the treatment of informal carers not engaged in market activities [10]. Some authors have delineated 'potential workers' and allocated a market wage to their lost time [10], whereas others have allocated a 'reservation wage' to carers not in paid employment, primarily the minimum wage [3]. The sociodemographic distribution of the underlying carer population also has the potential to have an impact on estimates. Characteristics such as age and sex are inextricably linked to labour force participation and market activity reimbursement and can impinge on informal care valuation.

Head and neck cancer (HNC) provides an interesting case study to examine the impact of these methodological issues. Carers are important in helping survivors deal with the significant medical, functional and psychosocial issues resulting from diagnosis and treatment [11, 12]. The majority of cases are diagnosed in men, hence most carers are women [13]. Risk factors have traditionally included tobacco smoking and alcohol consumption linked to lower socioeconomic status; however, recent evidence points to a growing role for infection with human papilloma virus, leading to a declining average age of diagnosis [13].

Our objective was to assess the impact of using alternative valuation methods, including the OCA, the generalist RCA (GRCA) and the specialist RCA (SRCA), to measure the cost of informal care for HNC. We also investigated the impact on costs of key assumptions underlying each approach, including the treatment of informal carers not in paid employment, the profile of carers and its link to market remuneration, and distinguishing household work from informal care.

Greater empirical assessment is required of the impact of the underlying sociodemographic and economic characteristics of carers on the subsequent costs derived for informal care, especially as the valuation literature expands and ranges across different disease types with increasing diversity in carer populations. Our study undertook an intensive exploration of one specific group of carers and investigated the impact of applying a range of alternative values to carer time depending on the specific underlying carer characteristic. The impact of these characteristics, and how they interact with methodological value judgments, to affect the cost of informal care time was highlighted. This will help to inform the importance of explicit awareness of the potential impact of valuation assumptions on diverse populations of carers, particularly those with a large proportion of older carers or unemployed carers, and inform the subsequent choice of valuation approach.

\section{Methods}

\subsection{Subjects}

This study was part of a larger project investigating the post-treatment experiences of HNC survivors in Ireland $[14,15]$. Surveys were initially sent to a population-based sample of 991 HNC survivors identified from the Irish National Cancer Registry in April 2012. A total of 583 completed surveys were received (response rate 59\%). Survivor respondents and non-respondents were similar (no significant differences) in terms of sex, cancer site, stage at diagnosis and time since diagnosis. However, respondents were younger than non-respondents $(p=0.01)$.

Consent was subsequently requested from survivors to contact their carer if they had one. Carers were defined as a family member, friend or another person who had helped take care of the HNC survivor post-diagnosis. Inclusion criteria included being (1) designated the primary caregiver by the survivor and (2) caring for their relative/friend for a minimum of 1 year post diagnosis. Questionnaires were subsequently sent to 285 carers between January and June 2014. There were 197 respondents (response rate 69\%), but 17 were excluded because consent was not received for sharing their questionnaire. Written consent was provided by the remainder of the study participants, and ethical approval was provided by participating hospitals.

\subsection{Questionnaire}

A questionnaire collected information on carer sociodemographic and economic characteristics in addition to the 
Table 1 Informal care categories

Support with household activities
Preparing food and drinks
Cleaning the house
Washing, ironing and sewing
Shopping
Maintenance work, odd jobs and gardening
Support with activities of daily living
Personal care
Moving around the house or going to the toilet
Eating and drinking
Support with instrumental activities of daily living
Making trips or visiting family or friends
Healthcare contacts
Organising help, taking care of financial matters like insurance
Cancer-specific activities
Including helping with managing pain, administering medicine,
etc.

respondent's relationship to the HNC survivor and whether the carer lived with the care recipient. Further questions asked the respondent how much extra time they spent per week in the past month on predefined caring activities outlined in Table $1[16,17]$.

\subsection{Valuation Methods}

\subsubsection{The Opportunity Cost Approach (OCA) and Replacement Cost Approach (RCA)}

The OCA assumes that time dedicated to informal caring could be allocated to other activities, including productive employment in the labour market, unpaid productive work or leisure time. Foregone time is generally valued at the individual's market wage or, in the case of non-market activity, a reservation wage measuring the rate at which a carer is willing to supply $1 \mathrm{~h}$ of paid labour [3]. The RCA values time dedicated to caring at the price of a market substitute [3, 4]. Approaches follow a GRCA that applies a single market wage of a substitute to all caring tasks or an SRCA that uses information on separate caring tasks and values these based on specific substitute market wages [10]. The limitations of each approach have been widely discussed [3, 5, 10, 18, 19].

Both the OCA and the RCA only include the value of carers' time, excluding, for example, out-of-pocket costs. Both approaches value caring hours equally even though the marginal valuation placed on different hours of care may differ [18]. In addition, although the OCA is the dominant approach applied in the literature [6] and therefore used as the base-case here, it tends to calculate different values for similar caring tasks depending on the carer who performs the task and assumes carers are free to choose their number of working hours [10]. Consequently, national statistical agencies such as Eurostat [20] have advocated the use of the RCA for national accounting purposes, an option explored in this study, and one that appears to minimise bias when estimating costs with a varied carer sociodemographic and economic profile. However, the RCA is not without criticism, including that the productivity of the informal carer may be at odds with the productivity (and therefore remuneration) associated with the market-based equivalent task $[3,10]$.

We used the reported total number of hours spent on domestic-related caring activity per carer per week in this study, with a 16-h threshold applied to hours spent caring per day to account for realistic carer waking hours as undertaken previously in the literature [7, 21]. All respondents were included in each valuation approach. Weekly estimates were aggregated to an approximate yearly total by multiplying weekly hours by 52 . Wage data were derived from the Structure of Earnings Survey (SES) [22] and stratified by sex, age and education. The SES is a 4-yearly survey based on a two-stage random sampling approach of enterprises (first stage) and employees (second stage) conducted for all EU member states and provides comparable information on earnings, individual characteristics of employees (e.g. sex, age, etc.) and their employer (economic activity, size of the enterprise, etc.) Gross wages were applied in mean and median form. Mean wages are often applied in the literature, but income distributions tend to be highly skewed, therefore using median wages can overcome the impact of very high wages disproportionately affecting mean wages [23]. Wage data from reference year 2010 were adjusted by Irish inflation to calculate 2014 wage rates.

The base-case cost $\left(\mathrm{OCA}_{1}\right)$ applied mean gross hourly wages in Ireland ( $€ 22.30$ per $h)$ to every respondent and their time allocated to care regardless of carer sex, age or employment status. Subsequent iterations of the OCA adjusted wages for sex $\left(\mathrm{OCA}_{2}\right)$, age $\left(\mathrm{OCA}_{3}\right)$, sex and age combined $\left(\mathrm{OCA}_{4}\right)$, and education $\left(\mathrm{OCA}_{5}\right)$. Table 2 presents the full range of wage rates used and the process of adjustment for each iteration. For example, $\mathrm{OCA}_{2}$ was constructed by applying mean sex-specific national hourly earnings to all male (wage €23.94) and female (wage $€ 20.62)$ informal care time.

An elementary occupation wage [24] was applied for the GRCA. Tasks performed by workers in elementary occupations include those by domestic cleaners and helpers. We derived an informal care cost according to the GRCA $\left(\mathrm{GRCA}_{1}: € 14.63\right.$ per $\left.\mathrm{h}\right)$, then adjusted by sex $\left(\mathrm{GRCA}_{2}\right)$ and sex and age combined ( $\left.\mathrm{GRCA}_{3}\right)$. 
Table 2 Description of informal care costing methods

\begin{tabular}{|c|c|c|}
\hline Costing approach & Code & Description \\
\hline \multicolumn{3}{|l|}{ OCA } \\
\hline General gross wage & $\mathrm{OCA}_{1}$ & $\begin{array}{l}\text { Mean }{ }^{\mathrm{a}} / \text { median national gross hourly earnings in } 2010(€ 22.30 / € 18.23) \text { applied to all carers- } \\
\text { Structure of earnings survey: hourly earnings } 2010\end{array}$ \\
\hline Sex adjusted & $\mathrm{OCA}_{2}$ & $\begin{array}{l}\text { Mean/median sex-specific national gross hourly earnings in } 2010 \text { (males: } € 23.94 / € 19.25 \text {; } \\
\text { females: } € 20.62 / € 17.32 \text { ) applied to all carers-Structure of earnings survey: hourly earnings } \\
2010\end{array}$ \\
\hline Age adjusted & $\mathrm{OCA}_{3}$ & $\begin{array}{l}\text { Mean/median age-specific national gross hourly earnings in } 2010(<30 \text { years: } € 15.14 / € 13.63 \text {; } \\
30-39 \text { years: } € 21.2 / € 18.51 ; 40-49 \text { years: } € 25.23 / € 20.30 ; 50-59 \text { years: } € 25.8 / € 20.46 \text {; } \\
\geq 60 \text { years: } € 21.89 / € 17.61) \text { applied to all carers-Structure of earnings survey: hourly } \\
\text { earnings } 2010\end{array}$ \\
\hline Sex and age adjusted & $\mathrm{OCA}_{4}$ & $\begin{array}{l}\text { Mean/median age-specific national gross hourly earnings in } 2010 \text {. Males }(<30 \text { years: } € 14.84 / \\
€ 13.47 ; 30-39 \text { years: } € 22.03 / € 18.95 ; 40-49 \text { years: } € 27.38 / € 21.84 ; 50-59 \text { years: } € 29.05 / \\
€ 22.64 ; \geq 60 \text { years: } € 24.47 / € 19.26) \text {. Females: }(<30 \text { years: } € 15.38 / € 13.75 ; 30-39 \text { years: } \\
€ 20.36 / € 18.13 ; 40-49 \text { years: } € 27.38 / € 19.02 ; 50-59 \text { years: } € 22.84 / € 18.62 ; \geq 60 \text { years: } € 19.30 / \\
€ 16.34) \text { Structure of earnings survey: hourly earnings } 2010\end{array}$ \\
\hline Education adjusted & $\mathrm{OCA}_{5}$ & $\begin{array}{l}\text { Mean/median education-specific national gross hourly earnings in } 2010 \text { (Primary: } € 16.79 / \\
\text { 14.93; secondary: } € 18.28 / € 15.83 \text {; third level: } € 25.94 / 22.13 \text {; postgraduate: } € 30.85 / € 26.14 \text { ) } \\
\text { applied to all carers-National Employment Survey hourly earnings } 2009 \text { (inflated values) }\end{array}$ \\
\hline \multicolumn{3}{|l|}{ GRCA } \\
\hline Elementary occupation & $\mathrm{GRCA}_{1}$ & $\begin{array}{l}\text { Mean/median national gross hourly earnings in } 2010 \text { for elementary occupations }(€ 14.63 \text { / } \\
€ 13.34) \text {. Structure of earnings survey: hourly earnings elementary occupations ISCO08 }\end{array}$ \\
\hline Adjusted by sex & $\mathrm{GRCA}_{2}$ & $\begin{array}{l}\text { Mean/median sex-specific national gross hourly earnings in } 2010 \text { for elementary occupations } \\
\text { (males: } € 15.50 / € 14.07 \text {; females: } € 13.47 / € 12.31 \text { ). Structure of earnings survey: hourly } \\
\text { earnings elementary occupations ISCO08 }\end{array}$ \\
\hline Adjusted by sex and age & $\mathrm{GRCA}_{3}$ & $\begin{array}{l}\text { Mean/median sex- and age-specific national gross hourly earnings in } 2010 \text { for elementary } \\
\text { occupations applied to household tasks, ADLs, IADLs and cancer-specific tasks. Structure of } \\
\text { earnings survey: hourly earnings elementary occupations ISCO08 }\end{array}$ \\
\hline \multicolumn{3}{|l|}{ SRCA } \\
\hline $\begin{array}{l}\text { Elementary occupation and } \\
\text { residential care activities }\end{array}$ & $\mathrm{SRCA}_{1}$ & $\begin{array}{l}\text { Mean/median national gross hourly earnings in } 2010 \text { with elementary occupations (€14.63) } \\
\text { wage applied to household tasks, and a residential care activities wage }(€ 17.88) \text { applied to } \\
\text { ADLs, IADLs and cancer-specific tasks - earnings hours and employment costs survey } \\
\text { quarterly } 2014\end{array}$ \\
\hline \multicolumn{3}{|l|}{ Sensitivity analyses } \\
\hline $\begin{array}{l}\text { General gross wage and minimum } \\
\text { wage }\end{array}$ & & $\begin{array}{l}\text { Mean/median national gross hourly earnings in } 2010(€ 22.30 / € 18.23) \text { applied to employed } \\
\text { carers, minimum wage of } € 8.65 \text { applied to carers not in paid work. Structure of earnings } \\
\text { survey: hourly earnings } 2010 \text { and minimum wage }\end{array}$ \\
\hline General gross wage and zero & & $\begin{array}{l}\text { Mean/median national gross hourly earnings in } 2010 \text { ( } € 22.30 / € 18.23) \text { applied to employed } \\
\text { carers, zero opportunity cost applied to carers not in paid work. Structure of earnings survey: } \\
\text { hourly earnings } 2010\end{array}$ \\
\hline
\end{tabular}

$\overline{A D L s}$ activities of daily living, GRCA generalist replacement cost approach, IADLs instrumental activities of daily living, ISCO08 Current version of the International Standard Classification of Occupations published in 2008, OCA opportunity cost approach, SRCA specialist replacement cost approach

${ }^{\text {a }}$ Base-case cost $=\mathrm{OCA}_{1}$ using mean wages

We applied the SRCA with a separate wage for different caring activities. The categories included an elementary occupation wage [24] applied to household tasks (HDLs) and a residential care activities wage (NACE Rev 2: sector 87, €17.88) [24] applied to activities of daily living (ADLs), instrumental activities of daily living (IADLs) and cancer-specific activities $\left(\mathrm{SRCA}_{1}\right)$.

In a separate scenario analysis, we applied median wages to our time estimates to account for the positively skewed distribution of wage data.

\subsection{Sensitivity Analyses}

We undertook two sensitivity analyses. We first investigated alternate costing options for informal carers not participating in the labour market at the time of the care recipient's cancer diagnosis through adjustment of the base-case OCA $\left(\mathrm{OCA}_{1}\right)$. This included applying a minimum wage to hours reported by informal carers not in paid work, and subsequently a zero opportunity cost. 
Our second analysis focused indirectly on the costing of carer household tasks. As discussed previously [5], measurement issues can arise if the carer lived with the care recipient before the diagnosis or if informal care was provided for several years prior to the diagnosis. In these cases it may be difficult for the respondent to separate informal care tasks from normal household activities. We consequently calculated costs separately for (1) carers who provided care to the recipient before the cancer diagnosis and those who did not and (2) carers who lived with the care recipient at the time of diagnosis and those who did not. Specifically, we hypothesised that carers who provided care to the recipient before the cancer diagnosis might not be able to distinguish ongoing household tasks from the additional tasks due solely to the new caring role and would overestimate their caring activities compared with those who did not. We also hypothesised that carers who lived with the care recipient at the time of diagnosis may overestimate their caring activities compared with those who did not, following the same logic.

\subsection{Statistical Analysis}

Means, medians and bootstrapped $95 \%$ confidence intervals were calculated for informal care costs. The bootstrapped method used the bias-corrected-accelerated approach and re-sampling 1000 times. The Wilcoxon signed rank test was computed to test for differences in costs in the sensitivity analyses.

\section{Results}

\subsection{Care Recipient and Informal Carer Characteristics}

Of the $583 \mathrm{HNC}$ survivors sampled in this study, $67 \%$ were male with a mean age of 63 years and were 5.4 years postdiagnosis on average. The characteristics of $180 \mathrm{HNC}$ informal carers are summarised in Table 3 . The majority were female $(76 \%)$, the survivor's spouse $(68 \%)$ and lived with the care recipient $(80 \%)$. Respondents' ages ranged from 23 to 85 years (mean 57.3) and almost three-quarters lived in a city, town or village. Approximately two-thirds were not in paid employment at the time of diagnosis (68\%), and one-third had completed third-level education. Almost three-quarters had not provided care prior to the HNC diagnosis $(72 \%)$.

\subsection{Informal Care Time Estimates}

Carers of HNC survivors spent $17.8 \mathrm{~h}$ on average per week performing care tasks (Table 4 ). The majority of time was
Table 3 Characteristics of HNC informal carers

\begin{tabular}{|c|c|c|}
\hline Variable & Frequency $^{\mathbf{a}}$ & $\%$ \\
\hline \multicolumn{3}{|l|}{ Gender } \\
\hline Male & 43 & 24 \\
\hline Female & 136 & 76 \\
\hline \multicolumn{3}{|l|}{ Employment status at time of diagnosis } \\
\hline Employed & 58 & 32 \\
\hline Looking after family/home & 47 & 26 \\
\hline Retired & 45 & 30 \\
\hline Other $^{\mathrm{b}}$ & 30 & 16 \\
\hline \multicolumn{3}{|l|}{ Comorbidity } \\
\hline No comorbid medical condition & 85 & 57 \\
\hline At least one comorbid medical condition & 63 & 43 \\
\hline \multicolumn{3}{|l|}{ Relationship to care recipient } \\
\hline Spouse & 122 & 68 \\
\hline Other & 58 & 32 \\
\hline \multicolumn{3}{|l|}{ Live with care recipient } \\
\hline Yes & 141 & 80 \\
\hline No & 35 & 20 \\
\hline \multicolumn{3}{|l|}{ Highest level of education completed } \\
\hline Primary & 28 & 16 \\
\hline Secondary & 90 & 51 \\
\hline Third level & 59 & 33 \\
\hline \multicolumn{3}{|c|}{ Provided care to care recipient prior to diagnosis } \\
\hline Yes & 56 & 33 \\
\hline No & 112 & 67 \\
\hline \multicolumn{3}{|l|}{ Carer location } \\
\hline City & 55 & 31 \\
\hline Town/village & 72 & 40 \\
\hline Countryside & 48 & 27 \\
\hline Unknown & 4 & 2 \\
\hline
\end{tabular}

${ }^{a}$ Numbers do not always add up to total respondents due to missing responses

b 'Other' category includes unemployed, unable to work due to permanent sickness or disability and students

allocated to household tasks (10.7 h), particularly preparing food/drink and cleaning the house (3.2 and $2.8 \mathrm{~h}$ ). Carers spent $2.3 \mathrm{~h}$ per week on ADLs, $4 \mathrm{~h}$ per week on IADLs and $1 \mathrm{~h}$ per week on cancer-specific tasks. Half of all carers reported undertaking at least one HDL task and one IADL task in the previous month. Less than half undertook ADL tasks (31\%) or cancer-specific care (17\%).

\subsection{Cost Estimates by Valuation Type: Mean Wages}

The estimated base-case annual cost of informal care was $€ 20,613\left(\mathrm{OCA}_{1}\right.$ using mean wages) (Table 5). Adjusting wages for informal carer characteristics (sex, age and education) resulted in estimates ranging between $+4.6 \%$ (age) and $-19.9 \%$ (education) of the base case. 
Table 4 Informal care time per week by activity with percentage of carers who undertook activity, means and boot strapped confidence intervals

\begin{tabular}{llrr}
\hline Category & $\begin{array}{l}\text { Percentage of carers who undertook } \\
\text { the task in the past month }\end{array}$ & $\begin{array}{l}\text { Mean hourly } \\
\text { time per week }^{\mathrm{a}}\end{array}$ & $\begin{array}{l}\text { Bootstrapped } \\
\text { confidence interval }^{-}\end{array}$ \\
\hline Cleaning the house & 37.3 & 2.8 & $2-3.7$ \\
Washing, ironing, sewing & 26.7 & 1.2 & $0.7-1.6$ \\
Shopping & 40.4 & 1.8 & $1.2-2.4$ \\
Maintenance work & 32.9 & 1.7 & $1.1-2.2$ \\
Preparing food and drink & 38.5 & 3.2 & $2.0-4.4$ \\
HDL & 50.9 & 10.7 & $7.9-13.2$ \\
Personal care & 12.4 & 0.9 & $0.3-1.4$ \\
Moving around house & 5.6 & 0.1 & $0.0-0.3$ \\
Eating and drinking & 8.1 & 0.6 & $0.1-1.2$ \\
ADL & 31.1 & 2.3 & $1.4-3.1$ \\
Making trips & 26.7 & 1.5 & $0.9-2.1$ \\
Healthcare contacts & 42.2 & 2.2 & $1.1-3.3$ \\
Organising help & 24.8 & 0.8 & $0.5-1.1$ \\
IADL & 50.0 & 4.0 & $2.9-5.2$ \\
Cancer-specific care & 17.4 & 1.0 & $0.5-1.1$ \\
Total & 63.0 & 17.8 & $14-21.9$
\end{tabular}

$A D L s$ activities of daily living, $H D L$ household tasks, IADLs instrumental activities of daily living

${ }^{a}$ Mean represents the average hourly time spent on each activity across all carers $(n=180)$

Annual informal care costs estimated by $\mathrm{GRCA}_{1}$ amounted to $€ 13,196$; this was $36 \%$ below the base case. Adjustments for sex and age had only minor effects on estimates $(-4.4$ and $-2.7 \%)$. The $\mathrm{SRCA}_{1}$ resulted in a value of $€ 14,196$ for informal care, $31 \%$ below the base case but $8 \%$ higher than GRCA $_{1}$.

\subsection{Scenario Analysis: Median Wage Valuation}

When median wages were applied, all OCA costs were 13-19\% lower than the equivalent mean wages estimate. The variability of estimates from the base case was also less (meaning costs were less sensitive to adjustment for sociodemographic characteristics). For the GRCA, the use of median wages also reduced the cost estimates, but by less than for the OCA, and reduced variability relative to the base case.

\subsection{Sensitivity Analysis}

Figure 1 presents the results of the first sensitivity analysis focusing on the treatment of carers not in paid employment. Applying the minimum wage to this group resulted in an estimated annual cost of $€ 12,574$, which was $39 \%$ below the base-case cost. This value fell to $€ 6812$ following the application of a 'zero' opportunity cost to this group (67\% below the base case).

A large difference in the cost of care was estimated for carers who provided care to their recipient before the cancer diagnosis $(€ 28,053)$ compared with those who did not $(€ 17,534)$, although this difference was not significant $(p=0.717)$, which may be due to sample size (Fig. 2). In the case of carers who lived with the care recipient, the difference was considerably smaller ( $€ 20,363$ for carers who lived with the care recipient vs. $€ 19,531$ for carers who did not; $p=0.374$ ).

\section{Discussion}

\subsection{Informal Care Costs and Carers Not in Paid Employment}

According to our base-case OCA estimate, the annual cost of informal care for HNC survivors was just over $€ 20,000$. With the exception of $\mathrm{OCA}_{4}$ (wages adjusted for age), this represents the highest value for informal care across all estimated methods. The base-case approach treats all informal carers (both in paid work and not in paid work) as a single homogenous group whose highest valued alternative forgone is paid work, compensated at the national mean wage. While adjusting wages for demographic factors and education did result in lower costs (e.g. 20\% reduction due to education adjusted wages), the largest single reduction was produced by the application of a zero cost to carers not engaged in market activity at the time of diagnosis (€6812; a reduction of $67 \%$ ). While this represents an extreme case, the base case may also be 
Table 5 Mean and median annual informal care costs by $\mathrm{OCA}^{\mathrm{a}}, \mathrm{GRCA}^{\mathrm{b}}$ and $\mathrm{SRCA}^{\mathrm{c}}$ with boot strapped confidence intervals and percentage change from the base-case $(2014 €)$

\begin{tabular}{|c|c|c|c|c|}
\hline Costing approach & & $\begin{array}{l}\text { Main analysis } \\
\text { Informal care cost - Mean wage } \\
\text { (bootstrapped } 95 \% \mathrm{CI}^{\mathrm{d}} \text { ) } \\
(\% \text { from base-case) }\end{array}$ & $\begin{array}{l}\text { Scenario analysis } \\
\text { Informal care cost - Median wage } \\
\text { (bootstrapped } 95 \% \mathrm{CI} \text { ) } \\
\text { (\% from base-case) }\end{array}$ & $\begin{array}{l}\% \text { difference between mean } \\
\text { and median values }\end{array}$ \\
\hline \multicolumn{5}{|l|}{ Opportunity Cost Approach } \\
\hline General gross wage & OCA1 & $\begin{array}{l}20,613^{\mathrm{e}} \\
15,906-25,061 \\
0 \%\end{array}$ & $\begin{array}{l}16,851 \\
13,202-20,996 \\
-18.3 \%\end{array}$ & $-18.3 \%$ \\
\hline Gender adjusted & OCA2 & $\begin{array}{l}18,913 \\
14,476-23,107 \\
-8.2 \%\end{array}$ & $\begin{array}{l}16,513 \\
12,937-20,512 \\
-19.9 \%\end{array}$ & $-12.7 \%$ \\
\hline Age adjusted & OCA3 & $\begin{array}{l}21,555 \\
16,692-26,888 \\
+4.6 \%\end{array}$ & $\begin{array}{l}17,490 \\
13,841-21,656 \\
-15.2 \%\end{array}$ & $-18.9 \%$ \\
\hline Gender and age adjusted & OCA4 & $\begin{array}{l}19,725 \\
15,280-24,444 \\
-4.3 \%\end{array}$ & $\begin{array}{l}16,382 \\
12,347-20,425 \\
-20.5 \%\end{array}$ & $-16.9 \%$ \\
\hline Education adjusted & OCA5 & $\begin{array}{l}16,511 \\
12,782-20,703 \\
-19.9 \%\end{array}$ & - & \\
\hline \multicolumn{5}{|l|}{$\begin{array}{l}\text { Generalist Replacement Cost } \\
\text { Approach }\end{array}$} \\
\hline Elementary occupation & GRCA1 & $\begin{array}{l}13,196 \\
10,355-16,381 \\
-36.0 \%\end{array}$ & $\begin{array}{l}12,032 \\
9,275-14,999 \\
-41.6 \%\end{array}$ & $-8.8 \%$ \\
\hline Gender adjusted & GRCA2 & $\begin{array}{l}12,604 \\
9,793-15,835 \\
-38.9 \%\end{array}$ & $\begin{array}{l}11,497 \\
8,989-14,255 \\
-44.2 \%\end{array}$ & $-8.8 \%$ \\
\hline Gender and age adjusted & GRCA3 & $\begin{array}{l}12,836 \\
9,901-16,010 \\
-37.7 \%\end{array}$ & $\begin{array}{l}11,882 \\
9,049-14,823 \\
-42.4 \%\end{array}$ & $-7.4 \%$ \\
\hline $\begin{array}{l}\text { Specialist Replacement Cost } \\
\text { Approach }\end{array}$ & & & & \\
\hline $\begin{array}{l}\text { Elementary occupation and } \\
\text { Residential care activities }\end{array}$ & SRCA1 & 14,196 & - & - \\
\hline & & $\begin{array}{l}10,837-17,843 \\
-31.1 \%\end{array}$ & - & - \\
\hline
\end{tabular}

${ }^{a}$ Opportunity Cost Approach

b Generalist Replacement Cost Approach

c Specialist Replacement Cost Approach

${ }^{\mathrm{d}}$ Confidence Interval

e Base case cost

${ }^{\mathrm{f}}$ Missing costs are due to a lack of wage data in sufficient detail for calculation purposes

considered excessive with its assumption of unlimited access to labour market opportunities for all carers.

Traditionally, the assumption underpinning the OCA is that each hour devoted to caring activities could be productively employed in the labour market. This standard assumption may not hold under labour market conditions with excess unemployment rates [10] where individuals cannot smoothly trade-off work and leisure time. As indicated by our results, the consequences of this on cost estimates can be significant. Even the use of minimum wages for this subgroup resulted in almost a $40 \%$ reduction in costs compared with the base case. 
(a)

0
-10
-20
-30
-40
-50
-60
-70
-80 (b)

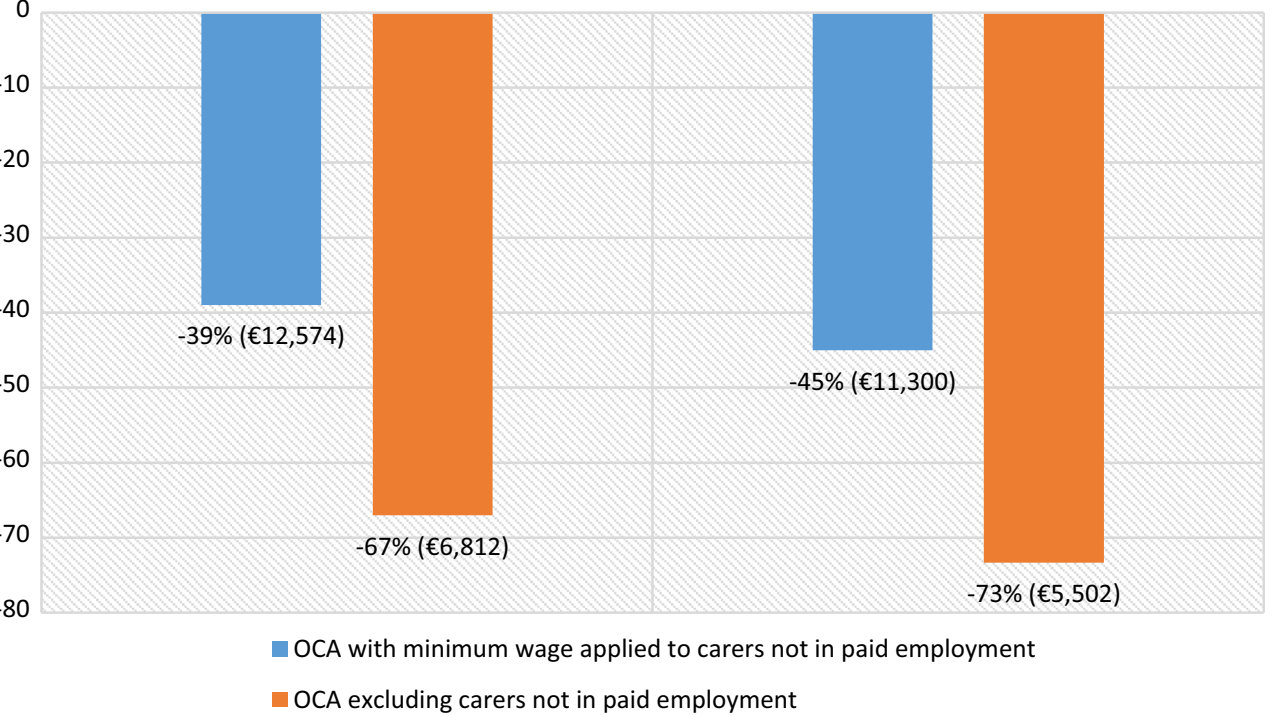

Fig. 1 Sensitivity analysis of informal care costs by different treatment of informal carers not in paid employment with percentage change from the base case [base-case cost $=€ 20,613$ ( OCA $_{1}$ using mean wages)] and monetary values using a mean wages and $\mathbf{b}$ median wages

(a)

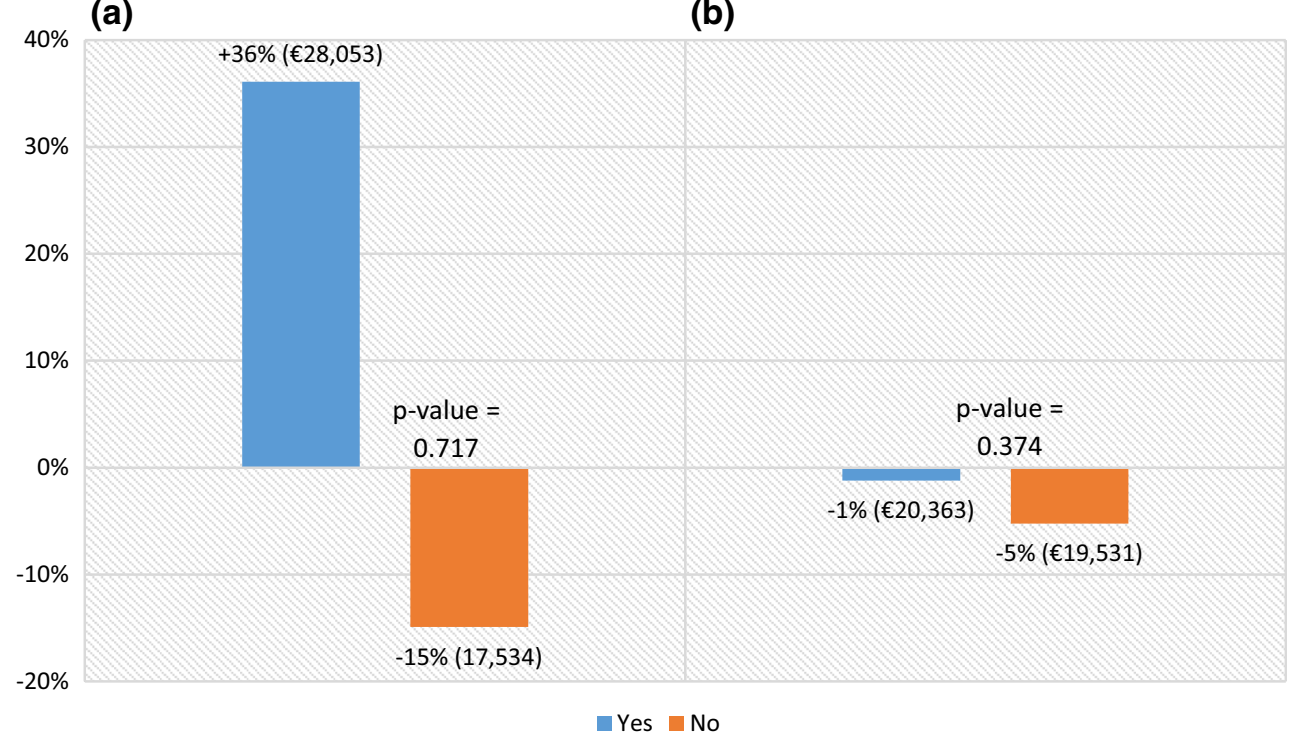

Fig. 2 Sensitivity analysis of informal care costs by different treatment of household tasks with percentage change from the base case [Base-case cost $=€ 20,613$ (OCA 1 using mean wages)],

A key driving factor of the economic characteristics of the carer population is their demographic profile. The majority of HNC carer participants were female (76\%), and one-third were above retirement age (33\%). This compares with $61 \%$ female and $25 \%$ above retirement age in the general carer population in Ireland [25]. This femaledominated and older age profile is not uncommon in cancer carer populations [26]. Females tend to have lower rates of labour force participation than males. Also, taking on the role of a primary carer can negatively affect the labour monetary values and $p$ values using a provided care to care recipient pre-diagnosis?; b lived with care recipient pre-diagnosis?

supply of females in particular [27]. Consequently, in informal carer populations dominated by females, proportionately more will tend not to be in paid employment. Older populations, and especially those above the official retirement age, also exhibit reduced labour force participation rates, further increasing the number of informal carers out of paid work.

Compared with the general population of carers in Ireland, HNC carers had lower levels of employment. For example, almost $59 \%$ of the general population of carers aged 
$>15$ years were in paid work [25] compared with $32 \%$ of HNC carers. Applying the general carer employment rate (59\%) to our cost estimates would increase informal care costs for the OCA with minimum wages applied to carers not in paid employment by $20 \%$. The $32 \%$ employment rate among HNC carers is also lower than for other cancer carer populations in Ireland, for example colorectal cancer (42\% employment rate [17]). For diseases with a disproportionate amount of carers who are older and out of paid work such as $\mathrm{HNC}$, attention is therefore required in choosing an appropriate version of the OCA. Assuming a zero cost or minimum wage cost for those not in employment will underestimate the true societal cost of informal care under such conditions. For this reason, we argue that a more realistic alternative might be to use the GRCA or the SRCA.

\subsection{RCA}

The value of informal care produced using the GRCA was $€ 13,196$. This approach valued time according to an average elementary occupation wage. Elementary occupations were remunerated at rates substantially lower $(€ 14.63)$ than more skilled professions, for example technicians and associate professionals ( $€ 22.76$ [24]). To help overcome this difference, we also applied the SRCA, which uses 'residential care' wage rates $(€ 17.88)$ for more specialised care tasks. Both approaches estimated informal care costs considerably below the base case (36 and 31\%, respectively).

The divergence between OCA and RCA estimates is driven by wages in market sectors perceived as 'female orientated' such as health and community services [28]. In female-dominated sectors, hourly wage rates tend to be far below those in more traditionally male-dominated sectors, but this does not necessarily reflect productivity differences [28]. Across Europe, this sex wage disparity increases with age [29]. As our analysis shows, using median wage rates rather than mean wages reduces this disparity somewhat but does not solve the underlying problem.

\subsection{Mean and Median Wage Issues}

Although there has been debate in relation to the choice of valuation approach for informal care [3-5, 18], few studies have examined the impact of using median rather than mean wage rates to value informal care time. Given that the distribution of wage data is positively skewed (towards high salaries [30]) across countries and labour market subgroups, the use of median wages would appear appropriate as a measure of the marginal revenue product of labour.

In Ireland, and across Europe, median wages have been lower than mean wages by between 17 and $20 \%$ across all age groups since 2002 [22]. In our study, the use of median wages decreased the cost of informal care from $€ 20,613$ in the base case to $€ 16,851$. Use of the median wage has an added advantage of reducing the heterogeneity in informal care costs across the different valuation approaches. This is useful given the number of revealed preference approaches that have been applied throughout the literature.

\subsection{The Treatment of Informal Care Household Work}

An important measurement issue relating to informal care is to distinguish normal household work from informal care [5]. This may be difficult, especially where the carer lives with the care recipient or has undertaken caring tasks prior to the cancer diagnosis. We analysed the carers' relationship to the care recipient and the effect this had on reported costs. Results revealed considerably different mean costs (albeit not statistically significant at this sample size) between carers who provided care to the recipient before the cancer diagnosis and those who did not but only a minimal difference between carers who lived with the care recipient prior to the cancer diagnosis compared with those who did not. In the former case, the difference may be indicative of a failure to distinguish routine household tasks from additional care tasks due solely to the cancer diagnosis. Some of the difference may be accounted for by the presence of comorbidities in the care recipient, which may exacerbate the care burden; we did not have information on care recipient comorbidities.

\subsection{Implications}

Our study revealed that normative-based value judgements had an even bigger impact on informal care costs than the choice of costing approach. Those undertaking informal care valuation should engage explicitly with implicit assumptions regarding the treatment of females, older carers and carers not in paid work. Further work is required to examine the effects of implicit assumptions and different valuation methods on carer populations with different sociodemographic and economic profiles than those explored here.

The use of labour market data to value the output of an essentially non-market activity is difficult. Costing methods based on revealed preference approaches such as the OCA and the RCA contain biases such as sex wage biases. In its current guise, traditional informal care costing transplants these biases more or less in place into non-market sectors. To limit this we suggest the use of the SRCA, using median wage rates, without adjustment for age, sex or education.

\subsection{Strengths and Limitations}

As far as we are aware, this study is the first in the informal care cancer valuation literature to investigate the results of 
valuing household tasks depending on the relationship of the carer to the care recipient and one of a limited number of studies to assess the impact of alternate approaches to valuing the time of carers not in paid employment [7-9]. While the response rate of $68 \%$ was relatively high for this type of survey, only carers nominated by the cancer survivor were invited to take part in the survey. We cannot be sure that any carers not nominated to take part share the same characteristics as our sample. In addition, although similar across a range of sociodemographic and diseaserelated variables, the respondents in the sample survivor cohort were younger than the non-respondent survivor cohort, which may have biased the results. Issues such as joint production where a carer may undertake two or more activities at the same time may be present in the data. In our sensitivity analysis, we attempted to account for aspects of this with our approach to valuing HDLs, but this error may also be present across other caring tasks. We did not distinguish between foregone paid work, unpaid productive work and leisure time in the OCA due to the recall design of the questionnaire and the subsequent postal survey undertaken. Respondents may differ in their understanding of unpaid time and leisure time, which is difficult to explain in a postal survey.

\section{Conclusion}

Our estimates of HNC informal care costs from a societal perspective reveal that, while the choice of costing method is important for monetary valuation, the sociodemographic and economic characteristics of the underlying population can be equally so, especially when they interact with normally implicit value judgements, for example the costing of carers not in paid employment at the time of the care recipient's diagnosis. More generally, the heterogeneous treatment of older carers, female carers and carers not in paid employment in the OCA can have a substantial impact on the resultant cost of estimated informal care unless these methods are standardised in the literature. To limit this, we suggest using the SRCA to value informal care across heterogeneous carer populations.

Data Availability Statement The datasets generated and analysed during the current study are not publicly available because of data protection restrictions. The study dataset includes data from the National Cancer Registry Ireland (NCRI); this is a Government body governed by statutory data protection guidelines. However, data may be formally requested from the NCRI subject to conditions.

Acknowledgements The authors thank the health professionals involved in this project for facilitating the survivor survey and supporting the local ethics applications. We also thank Dr Aileen Timmons in her role as study co-ordinator and for undertaking the data collection. Finally, we also appreciate the helpful advice provided by
Dr Rachael Gooberman-Hill and Dr Phyllis Butow as members of the steering committee on the SuN project.

Author contributions $\mathrm{PH}$ conceived and designed the study. MB collected the sample data. PH, LS, RM, EOS and MB contributed to the development of paper structure. PH and LS contributed to the development of analysis strategy. PH ran the analysis. PH wrote the first draft, and all authors contributed to subsequent revisions. All authors contributed to the critical revision of intellectual content in the final manuscript. All authors approved the final version for submission.

\section{Compliance with Ethical Standards}

Ethical approval All procedures performed in studies involving human participants were in accordance with the ethical standards of the institutional and/or national research committee and with the 1964 Helsinki declaration and its later amendments or comparable ethical standards. Ethical approval was provided by all participating hospitals.

Informed consent Informed consent was obtained from all individual participants included in the study.

Funding Funding for the collection of the data used in this study was supplied by the Irish Health Research Board (HRA/2009/262; HRA/ 2009/262/R).

Conflicts of interest Paul Hanly, Rebecca Maguire, Myles Balfe, Eleanor O'Sullivan and Linda Sharp have no conflicts of interest.

\section{References}

1. Riedel M, Kraus M. Informal care provision in Europe: regulation and profile of providers. European Network of Economic Policy Research Institutes (ENEPRI). ENEPRI research report no. 96. 2011. http://www.ancien-longtermcare.eu/sites/default/files/RR\% 20No\%2096\%20_ANCIEN_\%20Regulation\%20and\%20Profile\% 20of $\% 20$ Providers $\% 20$ of $\% 20$ Informal $\% 20$ Care.pdf. Accessed 4 May 2016.

2. Krol M, Papenburg J, Van Exel J. Does including informal care in economic evaluations matter? A systematic review of inclusion and impact of informal care in cost-effectiveness studies. Pharmacoeconomics. 2015;33(2):123-35.

3. Koopmanschap MA, Van Exel J, van den Berg B, Brouwer WB. An overview of methods and applications to value informal care in economic evaluations of healthcare. Pharmacoeconomics. 2008;26(4):269-80.

4. Krol M, Brouwer WB, Rutten F. Productivity costs in economic evaluations: past, present, future. Pharmacoeconomics. 2013;31 (7):537-49.

5. van den Berg B, Werner BF, Koopmanschap MA. Economic valuation of informal care: an overview of methods and applications. Eur J Health Econ. 2004;5(1):36-45.

6. Oliva-Moreno J, Trapero-Bertran M, Peña-Longobardo M, del Pozo-Rubio R. The valuation of informal care in cost-of-illness studies: A literature review. Pharmacoeconomics. 2016. doi:10. 1007/s40273-016-0468-y (epub ahead of print).

7. Hanly P, Céilleachair AÓ, Skally M, O'Leary E, Staines A, Kapur K, Fitzpatrick P, Sharp L. Time costs associated with informal care for colorectal cancer: an investigation of the impact of alternative valuation methods. Appl Health Econ Health Policy. 2013;11(3):193-203. 
8. Wimo A, Jönsson L, Fratiglioni L, Sandman PO, Gustavsson A, Sköldunger A, Johansson L. The societal costs of dementia in Sweden 2012-relevance and methodological challenges in valuing informal care. Alzheimers Res Ther. 2016;8(1):59.

9. Oliva-Moreno J, Peña-Longobardo LM, Vilaplana-Prieto C. An estimation of the value of informal care provided to dependent people in Spain. Appl Health Econ Health Policy. 2015;13(2): 223-31.

10. Giannelli GC, Mangiavacchib L, Piccolib L. GDP and the value of family caretaking: how much does Europe care? Appl Econ. 2011;44(16):2111-31.

11. Ross S, Mosher CE, Ronis-Tobin V, Hermele S, Ostroff JS. Psychosocial adjustment of family caregivers of head and neck cancer survivors. Support Care Cancer. 2010;18(2):171-8.

12. Baghi M, Wagenblast J, Hambek M, Radeloff A, Gstoettner W, Scherzed A, Spaenkuch B, Yuan J, Hornung S, Strebhardt K, Knecht R. Demands on caring relatives of head and neck cancer patients. Laryngoscope. 2007;117(4):712-6.

13. National Cancer Registry Ireland (NCRI). Cancer in Ireland 1994-2013: Annual Report of the National Cancer Registry. Cork: NCR; 2015. http://www.ncri.ie/sites/ncri/files/pubs/ NCRReport_2015_final11122015.pdf. Accessed 5 August 2016.

14. Pearce A, Timmons A, O'Sullivan E, Gallagher P, GoobermanHill R, Thomas AA, Molcho M, Butow P, Sharp L. Long-term workforce participation patterns following head and neck cancer. J Cancer Surviv. 2015;9(1):30-9.

15. Thomas AA, Timmons A, Molcho M, Pearce A, Gallagher P, Butow P, O’Sullivan E, Gooberman-Hill R, O'Neill C, Sharp L. Quality of life in urban and rural settings: a study of head and neck cancer survivors. Oral Oncol. 2014;50(7):676-82.

16. van den Berg B, Spauwen P. Measurement of informal care: an empirical study into the valid measurement of time spent on informal caregiving. Health Econ. 2006;15(5):447-60.

17. Hanly P, Céilleachair AÓ, Skally M, O’Leary E, Kapur K, Fitzpatrick P, Staines A, Sharp L. How much does it cost to care for survivors of colorectal cancer? Caregiver's time, travel and out-of-pocket costs. Support Care Cancer. 2013;21(9):2583-92.

18. Hoefman RJ, van Exel J, Brouwer WB. How to include informal care in economic evaluations. Pharmacoeconomics. 2013;31(12): 1105-19.

19. Goodrich K, Billingsley K, Al-Janabi H. The inclusion of informal care in applied economic evaluation: a review. Value Health. 2012;15(6):975-81.
20. Eurostat. Household production and consumption proposal for a methodology of household satellite accounts, Technical Report, Eurostat, Working Papers and Studies. 2003. http://ec.europa.eu/ eurostat/en/web/products-statistical-working-papers/-/KS-CC-03003. Accessed 4 July 2015.

21. Yabroff KR, Kim Y. Time costs associated with informal caregiving for cancer survivors. Cancer. 2009;115(18 Suppl):4362-73.

22. Eurostat. Structure of Earnings Survey, 2010. http://ec.europa.eu/ eurostat/data/database. Accessed 4 March 2016.

23. Eurostat. Statistics explained. Living standard statistics. http://ec. europa.eu/eurostat/statistics-explained/index.php/Living_standard_ statistics. Accessed 12 Jan 2017.

24. Central Statistics Office. Earnings hours and employment costs survey quarterly/EHQ15: 2014 elementary occupation wages. http://www.cso.ie/px/pxeirestat/database/eirestat/EHECS\%20 Earnings\%20Hours\%20and\%20Employment\%20Costs\%20Survey \%20Quarterly/EHECS\%20Earnings\%20Hours\%20and\%20Employment\%20Costs\%20Survey\%20Quarterly_statbank.asp?SP=EHECS $\% 20$ Earnings $\% 20$ Hours $\% 20$ and $\% 20$ Employment $\% 20$ Costs $\%$ 20Survey\%20Quarterly\&Planguage $=0$. Accessed 8 March 2016.

25. Central Statistics Office. Census 2011 profile 8 our bill of health - health, disability and carers in Ireland. http://www.cso. ie/en/census/census2011reports/census2011 profile8ourbillofhealthhealthdisabilityandcarersinireland/. Accessed 4 Jan 2017.

26. Colombo F, et al. Help wanted? Providing and paying for longterm care. OECD Publishing. 2011. https://www.oecd.org/els/ health-systems/47836116.pdf. Accessed 25 April 2016.

27. Johnson RW, Lo Sasso AT. The impact of elder care on women' labor supply at midlife. Inquiry. 2006;43(3):195-210.

28. Elborgh-Woytek K, Newiak M, Kochhar K, Fabrizio S, Kpodar $\mathrm{K}$, Wingender P, Clements B, Schwartz G. Women, work, and the economy: Macroeconomic gains from gender equity. IMF Staff Discussion Note. 2013. http://www.imf.org/external/pubs/ft/sdn/ 2013/sdn1310.pdf. Accessed 25 July 2016.

29. European Commission. Tackling the gender pay gap in the European Union. Luxembourg: Publications Office of the European Union; 2013. http://ec.europa.eu/justice/gender-equality/ files/gender_pay_gap/gpg_brochure_2013_final_en.pdf. Accessed 30 July 2016.

30. Neal D, Rosen S. Theories of the distribution of earnings. In: Atkinson $\mathrm{AB}$, Bourguignon $\mathrm{F}$, editors. Handbook of Income Distribution. Amsterdam: Elsevier Science BV; 2000. p. $379-427$. 